Check for updates

The BMJ

fgodlee@bmj.com Follow Fiona on Twitter @fgodlee

Cite this as: $B M / 2021 ; 375: n 2812$ http://dx.doi.org/10.1136/bmj.n2812 Published: 18 November 2021

\title{
Investing in public health is our best route to sustainable healthcare
}

\section{Fiona Godlee editor in chief}

Has it all been worth it: the handwashing, the mask wearing, the standing $2 \mathrm{~m}$ apart? The available evidence suggests it has. A systematic review published this week finds that these measures have reduced transmission of SARS-CoV-2 and deaths from covid-19 (doi:10.1136/BMJ-2021-068302). ${ }^{1}$

The conclusions are encouraging, but the paucity of good evidence for public health interventions during the pandemic is not. Among 35 studies good enough to evaluate, only one was a randomised trial, and it was too small (doi:10.1136/bmj.n2729). ${ }^{2}$ The others were all observational studies, including natural experiments, and the effects are likely to result from "bundles" of protective behaviours rather than single interventions.

We lack even this level of evidence to weigh up the benefits and harms of lockdowns, quarantine, isolation, closures of borders, schools, and workplaces, or increased indoor ventilation and outdoor socialising. This evidence deficit is one of the research tragedies of the pandemic, say Paul Glasziou and colleagues (doi:10.1136/bmj.n2729). ${ }^{2}$ Only $4 \%$ of the world's funding for covid-19 research has gone into public health measures. Better studies are on the horizon, in particular two large cluster randomised trials of mask wearing in Bangladesh and Guinea-Bissau. Better evidence should encourage more informed decision making.

Might it also improve the quality and civility of scientific debate, giving us something to get our teeth into rather than each other? The pandemic's evidence vacuum has certainly contributed to the bitterness of the pandemic debate (doi:10.1136/bmj.m3979). ${ }^{3}$ But doctors have always been rude to each other, says Agnes Arnold-Forster (doi:10.1136/bmj.n1888), 4 and the tenor of the current debate is not a product of the pandemic. We shouldn't deny the emotional, cultural, and political nature of medicine and science, she says. Indeed we should lean towards politics rather than turning away.

So, let's lean into the politics of healthcare funding. The UK spends less of its GDP on health than European comparators, with fewer doctors, nurses, and hospital beds per head than Germany and France. We are in the midst of an escalating staffing crisis (doi:10.1136/bmj.n2810, doi:10.1136/bmj.n2799), ${ }^{56}$ for which the government's spending plans are wholly inadequate (doi:10.1136/bmj.n2723, doi:10.1136/bmj.n2587. ${ }^{78}$ Those currently working in the service are stretched far beyond what is reasonable or safe, for them or their patients. Poor quality of care quickly becomes normalised, says Mary Dixon-Woods in the first episode of our new Doctor Informed podcast (bmj.com/podcasts/doctorinformed). ${ }^{9}$ We must fight against this (doi:10.1136/bmj.n2767). ${ }^{10}$
How can we make healthcare more sustainable, for those working in it, for national economies, and for the planet (doi:10.1136/bmj-2021-067199)? ${ }^{11}$ Here are two things we must do. First, we must stop providing low value interventions, where the harms or costs outweigh the benefits (doi:10.1136/bmj.n117, doi:10.1136/bmj.m2752). ${ }^{12} 13$ Tight control of type 2 diabetes in elderly people is one example (doi:10.1136/bmj-2021-066061), ${ }^{14}$ and you'll find more ideas and inspiration in another podcast launched this week, the Recovery (doi:10.1136/bmj.n2758, https://sustainablehealthcare.cochrane.org/podcastrecovery). ${ }^{1516}$ Second, because any healthcare system will fall over unless we improve the health of populations, we must press our political leaders to invest in public health.

Talic S, Shah S, Wild H, etal. Effectiveness of public health measures in reducing the incidence of covid-19, SARS-CoV-2 transmission, and covid-19 mortality: systematic review and meta-analysis. BMJ 2021;375:e068302.

2 Glasziou P, Michie S, Fretheim A. Public health measures for covid-19. BMJ 2021;375:n2729.

3 Davey Smith G, Blastland M, Munafò M. Covid-19's known unknowns. BMJ 2020;371:m3979. doi: 10.1136/bmi.m3979 pmid: 33077431

4 Arnold-Forster A. Polarisation, incivility, and scientific debate during covid-19-an essay by Agnes Arnold-Forster. BM/2021;374:n1888. doi: 10.1136/bmi.n1888 pmid: 34429297

5 Rimmer A. Physician vacancies are at highest level in almost a decade, colleges find. BMJ 2021;375:n2810doi: 10.1136/bmj.n2810 .

6 lacobucci G. RCGP disputes health secretary's claim that A\&E pressure is due to lack of GP appointments. BMJ2021;375:n2799. doi: 10.1136/bmj.n2799 pmid: 34782332

7 Bailey S. NHS staffing: the longest wait of all. BMJ2021;375:n2723. doi: 10.1136/bmj.n2723 pmid: 34753782

$8 \quad \mathrm{Ham}$ C. There is still time to save the NHS, but time is running out. BMJ 2021;375:n2587. doi: 10.1136/bmi.n2587 pmid: 34686492

9 Doctor Informed: beyond medical knowledge. https://www.bmj.com/pod casts/doctorinformed.

10 Morgan M. Matt Morgan: Sitting on the bin. BMJ 2021;375:n2767doi: 10.1136/bmi.n2767

11 Bhopal A, Norheim OF. Priority setting and net zero healthcare: how much health can a tonne of carbon buy?BM/2021;375:e067199. doi: 10.1136/bmj-2021-067199 pmid: 34711584

12 Brownlee SM, Korenstein D. Better understanding the downsides of low value healthcare could reduce harm. BMJ2021;372:n117 doi: 10.1136/bmj.n117 pmid: 33757999

13 Moynihan R, Johansson M, Maybee A, Lang E, Légaré F. Covid-19: an opportunity to reduce unnecessary healthcare. BMJ2020;370:m2752 doi: 10.1136/bmi.m2752 pmid: 32665257

14 Aubert CE, Lega IC, Bourron 0, Train AJ, Kullgren JT. When and how to deintensify type 2 diabetes care. BMJ 2021;375:e066061. doi: 10.1136/bmj-2021-066061 pmid: 34740903

15 Johansson M, Godlee F, Moynihan R. The Recovery-a podcast about action for sustainable healthcare. BMJ2021;375:n2758 doi: 10.1136/bmj.n2758 pmid: 34776410

16 Godlee F, Moynihan R. The recovery: action towards sustainable healthcare. https://sustainablehealthcare.cochrane.org/podcast-recovery. 